INTERNATIONAL CONFERENCE ON COMMUNICATION AND MEDIA 2020

\title{
INNOVATION, STRATEGIC COMMUNICATION AND SUSTAINABILITY: THE CASE FOR COMMUNICATION CHANGE
}

\author{
Norhafezah Yusof (a)*, Nor Aziah Mehat (b), Akmariela Ahmad Sayuti (c), Junaidah Yusof (d), \\ Mohammed Jasim Mohsin Al Jasim (e) \\ *Corresponding author \\ (a) Universiti Utara Malaysia, Kedah, Malaysia, norhafezah@uum.edu.my, \\ (b) Universiti Utara Malaysia, Kedah, Malaysia, azieh@uum.edu.my, \\ (c) Pejabat Menteri Besar Perlis, Malaysia, akmariela@perlis.gov.my, \\ (d) EDC Sintok, Kedah, Malaysia, junaidah224466@gmail.com, \\ (e) Universiti Utara Malaysia, Kedah, Malaysia, mohammedjassim101@gmail.com
}

\begin{abstract}
This study explores innovation and communication strategies of staff members in a research-based organization. Innovation drives organizational change. Smart communication strategies facilitate positive changes in an organization. Focus group was utilized in this study. Fourteen respondents were interviewed that consist of research, administrators, and skilled staff. Based on thematic analysis, the findings suggested that experiential knowledge, organizational practice and positive attitude are central in ensuring transfer of innovation is sustainable to the targeted community. Drawing on Roger's diffusion innovation theory and Lewis change communication approach, we propose that in introducing and sustaining innovation from an organization to a selected community, the organization has to convince the stakeholders on the utility of the innovation (product outcome), continuous support (after service innovation product) and accurate information about the product. This study offers theoretical and practical perspectives on how innovation could be introduced and sustained in a selected community via strategic communication approach.
\end{abstract}

2357-1330 @ 2021 Published by European Publisher.

Keywords: Communication change, experiential knowledge, focus group, innovation, organizational practice, positive attitude 


\section{Introduction}

The landscape of organizational sustainability has changed due to organic and planned strategies locally and globally. For an organization to be competitive and sustainable, it requires systematic strategic planning. This scenario heightens the critical role of innovation to spearhead a research-based organization forward thinking and creativity. Innovation is a process whereby new ideas are introduced, and new practices are adopted with the aim to produce meaningful outcome for relevant stakeholders. It serves as primary economic and social capital growth globally (French et al., 2014). Thus, an organization should catalyse on the innovative culture. The innovation culture is a value that shapes innovative thinking natural within the organization and encourages innovation activities in an organization. Davies and Buisine (2018) state that based on the literature analysis of innovation culture, there are five main factors that spearhead innovation: "the presence of innovative leaders and managers; the presence of innovative teams; the presence of innovative individuals; an organizational context conducive to innovation; multiple and easy links with outside of the organization" (p. 3)

Roger's Diffussion Innovation Theory offers a structured communication change approach when dealing with innovation. Grounding on successful innovation adoption principle, Roger (2003) states five main elements that could determine how adoption could be materialized. They are relative advantage of the innovation entity, compatibility with the targeted subject matter, complexity degree of the innovation usefulness, trialability degree of the utility of the innovation and observability of the innovation outcome. From the communicative perspective, Stakeholder theory is a theory of change in organisational communication which is suitable for this study. It caters a wide perspective on how an organisation can anticipate, coordinate, and reflect on change that affects the life of the organisation. Stakeholder theory is a theory that emphasises on how a stakeholder impacts the organisation/institution. Edward Freeman (1984) advocated on the importance of alignment of organisational needs with stakeholders' requirements. Drawing from Freeman's idea on stakeholder, Lewis (2011) proposed the model of communication change. Her main concern was on the stakeholders' perspectives on providing the most appropriate feedback and reflection on the evolution of change in an environment and onto the institution. The model argues that each stakeholder plays an important role in providing reflection on how matters can be solved based on their experiences and exposure.

\section{Problem Statement}

Studies in strategic communication and innovation have argued on the pivotal roles of leadership (Zerfass \& Huck, 2007), organizational culture (Marchiori \& Bulgacov, 2015) and organizational complexity (Heide et al., 2018) in influencing how innovation can be adopted. Looking from micro perspective, it is interesting to see how studies focus on human values such as leadership shapes how an innovation is successfully adopted or vice versa (Durst \& Poutanen, 2013). Moreover, there is a call that there is a need to study how organizational culture and employee empowerment determine success in transferring innovation to the targeted subject matter from communication framework (Choi, 2019). Thus, 
this study will explore innovation and communication strategies of employees in a research-based organization based on strategic communication approach.

\section{Research Questions}

Following are the research questions of this study:

- What are the innovation strategies used by the staff?

- How do the innovation strategies being delivered to the targeted recipient?

\section{Purpose of the Study}

The aim of this study is to explore innovation and communication strategies of staff members in a research-based organization based on strategic communication approach. Thus, the specific aims of the study are:

- To explore the innovation strategies used by the staff

- To understand communication strategies used by the staff to transfer the innovation to the targeted recipients

\section{Research Methods}

This study uses qualitative approach to fulfil its research aim. Fourteen respondents were interviewed that consist of research, administrators, and skilled staff. The sample selection was based on the criteria stated by the researchers. The criteria were their expertise in their designated posts and, working experiences. Their names were recommended by the manager based on the stated criteria. The interview protocol was developed from the literature review and was validated by an expert. Examples of questions asked are: Can you share with us your valuable experience regarding innovation product? What do you understand about innovation process/procedure? Why do you think your organization need it? Each focus group consisted of 7 respondents. Each session was conducted separately with the help of a moderator and an assistant. Each session was tape recorded. Each session lasted for an hour to two hours. The data was analysed using Clarke and Braun (2013) thematic analysis. There are six analysis steps in Clarke and Brown. Firstly, the researchers reviewed the data and coded important themes. Secondly, the themes were mapped against the whole data set of the research. Thirdly, the selected codes were finalized into specific main codes that were aligned to the research focus. Fourthly, the codes were rereviewed to ensure their consistency. Fifthly, the finalized themes were determined after rounds of intense discussions of the team members. Finally, the comprehensive report was prepared based on the robust analysis of the data.

\section{Findings}

Based on the analysis, the data revealed the key findings of the study: 1) Innovation strategies and 2) Communication strategies. Both have two themes, respectively. 


\subsection{Innovation strategies}

- Testing at multiple places

- Problem solving approach

\subsection{Communication strategies in transferring innovation}

- Optimize social media usage to deliver innovation

- Participate in competition

For innovation strategies, it was found that multiple sites testing, and adaptive problem-solving approach facilitate how innovation can be transferred to the targeted recipients. As stated by the respondent A: "It is vital to do multiple sites testing to ensure the feasibility and practicality of the innovation product. We need to provide essential empirical evidence to prove that our product is innovative and practical to the users". A resilient innovation is verified via multiple sites testing according to majority of the respondents. By multiple testing, it indicates the suitability of the innovation entity that will be shared with the targeted users. Another theme is flexible problem-solving approach that is not rigid yet offer systematic procedure for other to replicate the innovation. The respondents stated the importance of anticipating potential problems, understanding the consequences of the problems, and providing context driven solutions. Respondent B argued: "Practically, we have to be creative in forecasting on potential problems. This is because, each problem is unique and requires specific problemsolving solution". The deliberation of problem-solving approach is closely associated with CAUSE model that is proposed by Rowan (2003). The model argues on the need to establish Confidence, develop Awareness, deepen Understand, obtain Satisfaction, and spur Enactment in managing risk-based communication matters. For both innovation strategies, they are categorized under routine strategy (Pisano, 2015). Routine strategy refers to upscaling innovation based on the mission and vision of the institutions. It is a client-based demand and within the direction of the management of the institution.

There are two main themes that indicated suitable communication strategies in transferring innovation that are utilizing social media platform and participating in competition. Social media is an effective communication platform to be used by the institution to transfer the technology to the potential users. The respondents explained about the positive impact of social media in showcasing the innovation to the mass. As mentioned by Respondent C: "Social media is the in thing now, we have to use Facebook, Instagram and Twitter that will promote the product and enhance the visibility of the product usefulness". Indirectly, there will be a spill over effect on the targeted stakeholders in attracting the targeted groups whom the institution intends to transfer the innovation. Another interesting strategy is through competing in innovation expos and exhibitions. Respondents also stated that by participating and competing in innovation events, it increases the chance of visibility of the innovation and thus, will attract users to adapt the innovation. As stated by Respondent D: "We have been competing in national and international competitions. We have gained lots of experiences in understanding other products and the same time, promoting our products to the other companies, organizations, and potential funders. 


\section{Conclusion}

Integrating the findings with Roger's Diffusion Innovation Theory and Stakeholder Model, the crux of successful innovation adaptation is ensuring feasibility and visibility of the innovation entity, stakeholder needs and applying contextual problem-solving approach. Thus, it is vital for an institution to strategize the communication plan in ensuring successful innovation strategies. Drawing from Roger (2003) five key elements, multi-site testing and flexible problem-solving approach offer sustainability of innovation transfer to the potential users. In strategizing communication approach, understanding and engaging the relevant stakeholders is important. In order to ensure the stakeholders continuous support in adapting the innovation, Lewis (2011) argues that the institutions have to realise the context of the stakeholders understanding on the innovation, readiness of adaptability and impact of the innovation onto the stakeholders.

Leading to change demands dynamic organizational culture and support from employees. Positive organizational values and supportive environment in facilitating innovation transfer will sustain quality strategic communication plan (Allevato, 2020; Büschgens et al., 2013). Employees are agents of change. They offer deep work commitment that could drive an organization to another level. Thus, by empowering the employees in their tasks enhance their trust levels towards the management and spur creativity among the employees. In line with the agenda of sustainability of change, to pursue a success story, the movement of change must start from the organization. Organizational culture is developed from ongoing values and norms that are shared and understood by the management and employees. Moreover, building up human capital will ensure strong commitment and positive knowledge transfer from the organization to the targeted community.

\section{Acknowledgments}

We would like to thank the respondents involved in this research. This paper was supported by a Matching Grant (S/O Code: 14676) and facilitated by the Research and Innovation Management, Universiti Utara Malaysia.

\section{References}

Allevato, E. (2020). Organizational culture change: growth mindset, positive psychology, and empowerment. In: Marques J., Dhiman S. (eds) Social entrepreneurship and corporate social responsibility. Management for Professionals. Springer, Cham. https://doi.org/10.1007/978-3030-39676-3_28

Büschgens, T., Bausch, A., \& Balkin, D. (2013). Organizational culture and innovation: A meta-analytic review. Journal of Product Innovation Management, 30(4), (2013), 1-19.

Choi, I. (2019). Moving beyond mandates: Organizational learning culture, empowerment, and performance. International Journal of Public Administration. https://doi.org/10.1080/01900692.2019.1645690

Clarke, V., \& Braun, V. (2013). Teaching thematic analysis: Overcoming challenges and developing strategies for effective learning. The Psychologist, 26(2), 120-123.

Davies, M., \& Buisine, S. (2018). Innovation culture in organizations. In M. Chouteau, J. Forest, \& C. Nguyen. Science, technology and innovation culture, 3. Washington: Iste. https://doi.org/10.1002/9781119549666.ch6 
Durst, S., \& Poutanen, P. (2013). Success factors of innovation ecosystems - Initial insights from a literature review. In: Smeds, R., Irrmann, O., (Eds.), Co-create 2013: The Boundary-Crossing Conference on Co-Design in Innovation. Aalto, Denmark, 27-38. http://www.academia.edu/4007245/Success_factors_of_innovation_ecosystems_A_literature_revi ew

Freeman. E. (1984). Strategic management: A stakeholder approach. Boston, MA: Pitman.

French, J., Karen Montiel, K., \& Palmieri, V. (2014). Innovation in agriculture: A key process for sustainable development. Inter-American Institute for Cooperation on Agriculture, San Jose, Costa Rica. http://repositorio.iica.int/bitstream/handle/11324/2607/BVE17038694i.pdf? sequence=1

Heide, M., von Platen, S., Simonsson, C., \& Falkheimer, J. (2018). Expanding the scope of strategic communication: Towards a holistic understanding of organizational complexity. International $\begin{array}{llll}\text { Journal of Strategic } & \text { Communication, } & \text { 12(4), }\end{array}$ https://doi.org/10.1080/1553118X.2018.1456434

Lewis, L. K. (2011). Organizational change: creating change through strategic communication. Chichester: Wiley-Blackwell.

Marchiori, M., \& Bulgacov, S. (2015). Strategy as communicational practice in organizations. In D. R. Holtzhausen \& A. Zerfass (Eds.), The Routledge handbook of strategic communication (pp. 190200). New York, NY: Routledge.

Pisano, G. P. (June, 2015). You need an innovation strategy. Harvard Business Review, 94(6), 44- 54.

Rogers, E. M. (2003). Diffusion of Innovations (5th ed.). New York: Free Press.

Rowan, K. E. (2003). Informing and explaining skills: Theory and research on informative communication. In J. O. Greene \& B. R. Burleson (Eds.), The handbook of communication and social interaction skills (pp. 403-438). Mahwah, NJ: Erlbaum

Zerfass, A., \& Huck, S. (2007). Innovation, communication, and leadership: New developments in strategic communication. International Journal of Strategic Communication, 1(2), 107-122. https://doi.org/10.1080/15531180701298908 